\title{
INOVAÇÕES TECNOLÓGICAS EM EDIFICAÇÕES HABITACIONAIS: AVALIAÇÃO PÓS-OCUPAÇÃO DAS VEDAÇÕES VERTICAIS
}

\author{
A. C. LORDSLEEM JR., H. R. ALMEIDA \\ Departamento de Engenharia Civil, Escola Politécnica, Universidade de Pernambuco, Recife, Brasil.
}

\section{RESUMO}

Este trabalho objetivou avaliar as paredes de concreto e drywall, obtendo informações sobre o desempenho e o grau de satisfação dos usuários. A metodologia contemplou pesquisa de estudo de caso em 2 empreendimentos residenciais no estado de Pernambuco/Brasil, através da avaliação pósocupação. Os resultados demonstraram que $31 \%$ dos usuários demonstraram baixa satisfação com o nível de desgaste já apresentado nas edificações com paredes de concreto; enquanto, $71 \%$ dos usuários demonstraram baixa satisfação com a acústica entre ambientes nas edificações com drywall. Os achados são limitados aos empreendimentos pesquisados; porém, com caráter original, sem precedentes na região. Como conclusão, a principal contribuição consistiu em identificar os fatores de satisfação que podem subsidiar novos projetos e atender as demandas dos usuários.

Palavras clave: Avaliação pós-ocupação; Inovações tecnológicas; Vedações verticais; Paredes de concreto; Drywall. 


\section{INTRODUÇÃO}

Um dos principais desafios enfrentados pela indústria da construção civil brasileira nesses últimos 15 anos vem sendo atender uma elevada demanda por edificações, marcada sobremaneira pelo elevado déficit habitacional de aproximadamente 6 milhões de moradias (FIESP, 2019), com a imperiosa necessidade de melhoria da qualidade das obras (MELLO; AMORIM, 2009; MORAIS, 2019), atendendo tanto os consumidores que investem em bens imobiliários, quanto os cidadãos de baixa renda assistidos por programas públicos de habitação.

Em resposta, inúmeras inovações tecnológicas foram implementadas na construção buscando suprir a carência de habitações e promover um patamar mais industrializado ao processo construtivo tradicional brasileiro, reconhecidamente responsável por parcela expressiva de desperdícios, baixa produtividade da mão de obra e problemas patológicos (PINHO, 2013; ALMEIDA et al., 2014).

As tecnologias construtivas inovadoras foram introduzidas ainda num ambiente do mercado de construção de edifícios caracterizado pela aceleração nos prazos de entrega das obras, o que de acordo com Almeida et al. (2014) foi agravado por planejamentos deficientes e controles precários, facilitando o surgimento de indesejadas manifestações patológicas.

De acordo com Campos (2011), na cidade de Vitória/ES, em 2007, umas médias de 6\% das 1,8 mil unidades entregues viraram queixas nos PROCONS; já em 2010, esse índice subiu para 15\% das 3 mil unidades entregues, aumento percentual e em números absolutos em função do crescimento de entregas de obras. O PROCON (2015) da cidade de São Paulo/SP apresentou em seu relatório do ano de 2013, quando comparado com o ano de 2008 , o crescimento em cerca de $400 \%$ no número de reclamações relacionadas à qualidade das edificações, tendo o aumento das queixas coincidido com o aquecimento do mercado imobiliário.

Por outro lado, o principal programa de habitação popular brasileiro Minha Casa Minha Vida (MCMV) entregou 54\% das moradias com manifestações patológicas, segundo levantamento realizado pela Controladoria-Geral da União (CGU) em parceria com o Ministério da Transparência em 77 empreendimentos e 1.472 unidades habitacionais em doze estados do país (BRASIL, 2017). O MCMV foi responsável por parcela expressiva das inovações tecnológicas introduzidas nas vedações verticais brasileiras nesta última década.

A preocupação quanto à qualidade foi potencializada pela publicação da norma de desempenho brasileira NBR 15575 (ABNT, 2013) que determinou requisitos e critérios a serem alcançados pelos subsistemas das edificações habitacionais.

Nesse contexto, as vedações verticais ganharam ainda mais importância, pois determinam grande parte do desempenho do edifício como um todo, por serem responsáveis pelos aspectos relativos ao conforto, à higiene, à saúde e à segurança de utilização. Além disso, as vedações verticais possuem estreita relação com a estrutura e as instalações e, não raras vezes, são responsabilizadas pelo aumento da incidência de manifestações patológicas nas edificações, causando níveis elevados de insatisfação aos seus usuários.

Algumas das principais inovações tecnológicas empregadas no subsistema vedações verticais são destacadas por Mello (2004); Bonin, Amorim (2006); CBIC (2014) e; Ecker, Martins (2014), quais sejam: paredes maciças de concreto armado, painéis pré-moldados em concreto convencional e leve, painéis mistos tipo sanduíche, painéis de chapas de fibra de vidro, chapas de aço galvanizado, painéis de PVC, drywall, steel frame, light steel frame e wood frame.

Dessas tecnologias, são exemplos de uso mais recente de vedações verticais inovadoras no Estado de Pernambuco, no nordeste do Brasil, as paredes maciças de concreto armado e o drywall (ALMEIDA, 2018). Embora essas vedações verticais tenham uso disseminado em outros países, são ainda consideradas inovadoras pois não dispunham até então de norma técnica brasileira para a análise de desempenho e não tinham tradição de uso no território nacional (MINISTÉRIO DAS CIDADES, 2019). 
De acordo com Almeida (2018), em Pernambuco não há registros de avaliações que permitam validar as inovações tecnológicas como solução técnica em relação à finalidade para a qual foi projetada, nem o atendimento pleno aos usuários, completando o ciclo de produção da edificação. Ainda são escassos os trabalhos que avaliem essas inovações tecnológicas empregadas no subsistema vedações verticais das edificações durante o período de uso, de maneira que as habitações possam ser melhoradas.

Este processo denomina-se de Avaliação Pós-Ocupação (APO), o qual possibilita a identificação do grau de satisfação do cliente final e seus fatores determinantes viabilizando a revisão das etapas anteriores ao uso e a adoção de medidas corretivas ou preventivas nos produtos avaliados ou futuros. A APO é um processo de avaliação de edifícios, passado algum tempo de sua construção e ocupação, focado nos ocupantes do edifício e as suas necessidades, a partir dos quais possibilita analisar as consequências das decisões de projeto no desempenho da edificação (RHEINGANTZ, 2009; ORNSTEIN, 2017).

Diante disto, percebe-se a importância deste trabalho, o qual busca aplicar a metodologia da avaliação pós-ocupação no subsistema vedação vertical em edificações, como forma de contribuir para a análise de desempenho agregada à satisfação dos usuários e a identificação de possíveis melhorias no modo de utilização e produção destas inovações.

Deste modo, este trabalho teve como objetivo principal realizar a avaliação pós-ocupação de tecnologias inovadoras utilizadas em vedações verticais, especificamente as paredes maciças de concreto armado e drywall, obtendo informações sobre o desempenho e o grau de satisfação dos usuários.

\section{METODOLOGIA}

As seguintes etapas sistematizam o fluxo de realização desta pesquisa de estudo de casos, as quais são descritas na sequência: definição das tipologias de vedação vertical a ser pesquisada, definição das amostras, elaboração de instrumentos de pesquisa (questionários), aplicação e adequação de questionário piloto, realização de entrevistas para aplicação do questionário com usuários, e por fim, compilação e análise dos resultados.

\subsection{Definição das tipologias de vedação vertical}

Os critérios adotados para a definição das tipologias construtivas de vedação vertical pesquisadas foram: localização no Estado de Pernambuco, publicações/informes técnicos que demonstrassem o emprego de vedações verticias inovadoras, informação disponibilizada pela gerência executiva de habitação do principal órgão financiador do sistema habitacional brasileiro - Caixa Econômica Federal e disponibilização para a realização da pesquisa. Como resultado, foram definidas as seguintes tipologias de vedações verticais inovadoras: paredes de concreto armado moldadas no local e em drywall.

\subsection{Definição das amostras}

Buscou-se identificar dois empreendimentos (2 estudos de casos), através de contatos com reconhecidas construtoras do mercado da construção, cada qual utilizando uma das vedações verticais alvo da pesquisa. Foi adotado o método não probabilístico - definição da amostra de entrevistados (usuários), mais adequado quando ocorre restrições operacionais como o fato de não se ter acesso a todos os elementos da mesma (LAKATOS; MARCONI, 2007). Além disso, adotou-se a amostragem por conveniência, como técnica que utiliza uma amostra de população que seja acessível no momento em que se quer realizar o estudo, aleatoriamente disponível (OCHOA, 2015). Apesar da impossibilidade de acesso às unidades habitacionais, buscou-se por meio da amostragem por conveniência - nas áreas comuns dos empreendimentos - realizar uma quantidade de entrevistas que abrangesse ao menos $20 \%$ da população em cada empreendimento pesquisado. 


\subsection{Elaboração dos instrumentos de pesquisa}

Foi elaborado questionário aplicado junto aos usuários das edificações, o qual buscou aferir o nível de satisfação em relação às vedações verticais da edificação e as implicações das vedações verticais em suas rotinas. O questionário foi dividido nos seguintes grupos de questões: os motivos de escolha da unidade, conforto ambiental, tecnologia construtiva das vedações verticais, uso e manutenção das unidades e satisfação com as vedações verticais.

\subsection{Aplicação e adequação do questionário piloto}

O questionário foi aplicado de forma piloto junto a três usuários do condomínio pesquisado no estudo de caso 1, que ao responderem as questões propostas contribuíram para o posterior aprimoramento do instrumento de pesquisa. Prosseguiu-se então a adequação e aprimoramento do instrumento de pesquisa com reformulação da redação de algumas questões, o que gerou maior entendimento e dinamismo quando o mesmo foi aplicado aos demais usuários dos condomínios dos estudos de casos 1 e 2 .

\subsection{Realização de entrevistas para aplicação do questionário com usuários}

As entrevistas foram realizadas após anuência dos síndicos dos empreendimentos, sendo autorizada a presença do pesquisador nas áreas comuns, acessando os apartamentos apenas quando liberado pelos usuários. As entrevistas referentes à pesquisa de estudo de caso 1, foram realizadas com usuários de 38 dentre as 189 unidades ocupadas, o que representa 20,1\% das unidades em uso. As entrevistas referentes à pesquisa de estudo de caso 2, ocorreram com usuários de 21 das 74 unidades ocupadas, o que representa $28,4 \%$ das unidades em uso.

\subsection{Compilação e análise dos resultados}

Os dados obtidos através das entrevistas realizadas foram compilados através da utilização de planilhas, onde foram organizados de acordo com as perguntas do questionário, de modo a facilitar o processo de análise.

\section{RESULTADOS}

\subsection{Estudo de caso 1}

\subsubsection{Caracterização do edifício com paredes de concreto moldadas no local}

O condomínio localiza-se na cidade de Paulista, no Estado de Pernambuco, no nordeste do Brasil. A área total do empreendimento é de $17.180,09 \mathrm{~m}^{2}$, composto por 19 edifícios, cada edifícios conforme Figura 1, sendo 4 pavimentos, configurando-se quatro unidades por pavimento, totalizando 304 unidades, das quais 189 encontravam-se ocupadas.

A obra teve início em agosto de 2015 e foi finalizada em agosto de 2016, tendo seu pico atingido a produção de quatro apartamentos por dia. A fundação dos edifícios foi executada em radier; enquanto, a estrutura utilizou dois conjuntos de formas metálicas.

\subsubsection{Motivo de escolha da unidade}

Os principais motivos de escolha da unidade habitacional elencados pelos respondentes foram em ordem decrescente: custo inferior do imóvel, localização do edifício e rapidez na execução da obra. Por se tratar de unidades de perfil popular e contar com subsídios do Programa Minha Casa Minha Vida do Governo Federal, o fator custo foi citado por 78,9\% dos usuários, pois tornou a aquisição dos imóveis viável a um grande número de famílias. 68,4\% dos respondentes afirmaram que a localização do conjunto próximo a avenida principal do bairro foi fator primordial para a escolha, devido à facilidade de acesso aos meios de transporte. Quanto à rapidez na execução, 42,1\% dos entrevistados se mostraram surpresos devido ao fato de a obra ter sido entregue em um prazo menor do que o acordado com a construtora no momento da compra do imóvel. 
a)

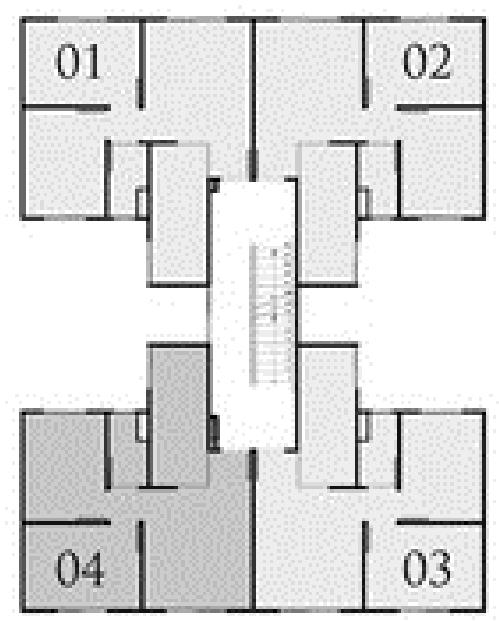

b)

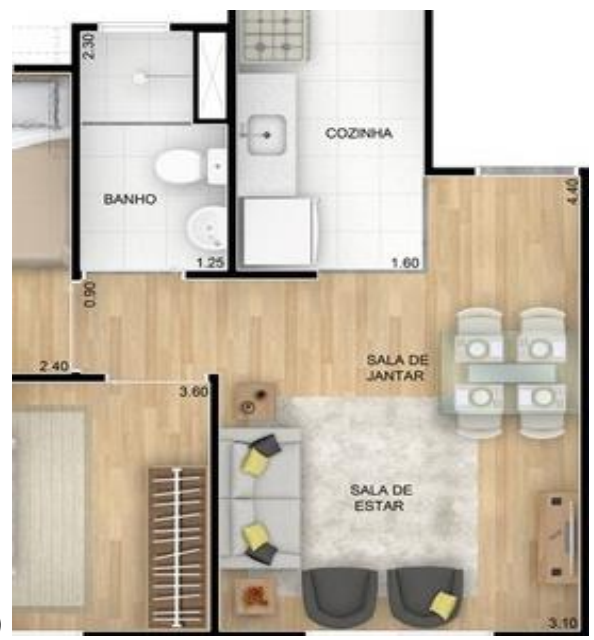

Figura 1. Planta baixa - estudo de caso 1: a) pavimento tipo, b) apartamento. Fonte: Construtora do estudo de caso 1 (2019).

\subsubsection{Conhecimento da tecnologia construtiva}

Dentre os 38 entrevistados, 95\% (36 respondentes) nunca haviam tido contato com a tipologia de vedação de seus imóveis e 5\% (2 respondentes), equivalente a um entrevistado, conheciam a tipologia de paredes monolíticas em concreto. Cabe ressaltar que este respondente indicou já ter trabalhado na mesma construtora que executou a obra de seu conjunto residencial, mas que este fato não o influenciou no momento de optar por comprar o imóvel.

\subsubsection{Conforto ambiental}

A Figura 2 ilustra o grau de satisfação dos usuários.

Divisões dos cômodos

Tamanho dos cômodos

Ventilação da edificação

Iluminação natural

Conforto térmico

Acústica em relação ao interior

Acústica em relação ao exterior

O que acha de morar aqui?

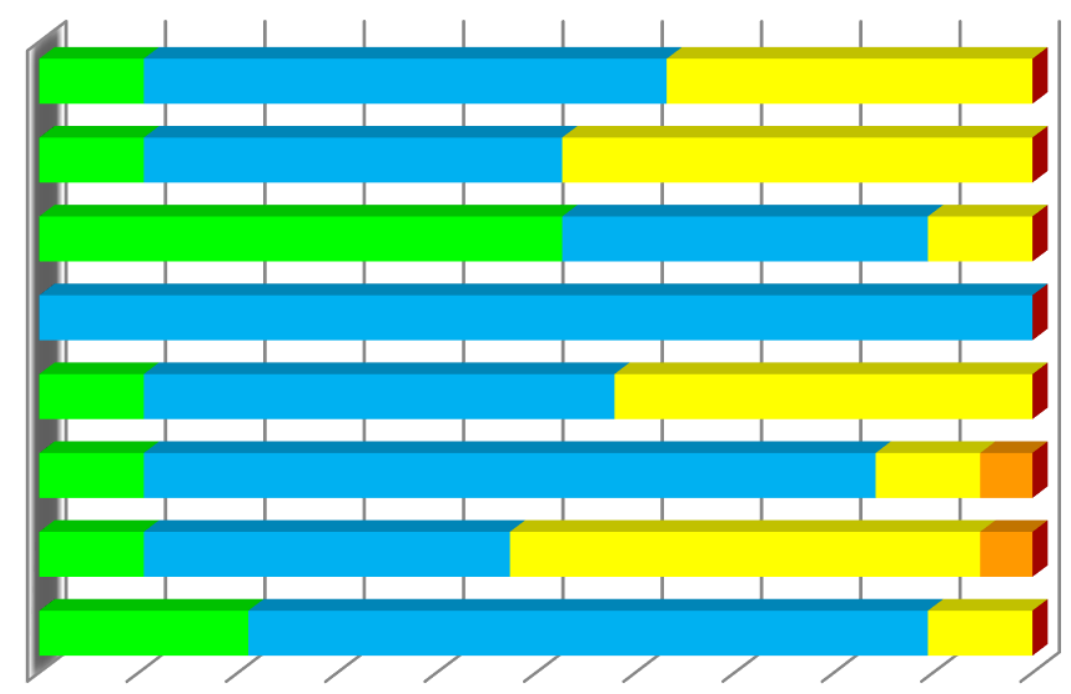

$\begin{array}{lllllllllll}0 \% & 10 \% & 20 \% & 30 \% & 40 \% & 50 \% & 60 \% & 70 \% & 80 \% & 90 \% & 100 \%\end{array}$

$\square$ Muito bom Bom Regular $\square$ Ruim $\square$ Muito ruim

Figura 2. Grau de satisfação dos usuários.

Fonte: Os autores (2019) 
Destacam-se nas respostas da Figura 2:

- a maioria dos entrevistados, $74 \%$ avalia como boa a experiência de morar em imóvel com paredes de concreto, apesar de reclamações relativas às manifestações patológicas e dificuldades de execução de novas instalações embutidas nas paredes;

- quanto às divisões dos cômodos, a maioria dos entrevistados se mostrou satisfeita, optando pela classificação "boa". Entretanto, diversos respondentes salientaram o fator negativo da sala de estar ter vistas diretas para o ambiente da cozinha, gerando uma diminuição do conforto ao recepcionar visitas;

- o tamanho dos cômodos teve avaliação "regular", porém a situação foi compensada pelo menor valor de compra oferecido pela construtora;

- o conjunto habitacional está situado em uma área onde são escassas as edificações verticais, e próximas a uma grande área de floresta, proporcionando assim uma boa ventilação, que foi classificada pela maioria dos usuários como "muito boa". Entretanto, por estar posicionado vizinho a outro conjunto habitacional, parte de seus edifícios tem a ventilação diminuída;

- A iluminação foi considerada como "boa" por todos os entrevistados, já o conforto térmico foi avaliado como "bom" por $47 \%$ dos respondentes e "regular" por $42 \%$. Equilíbrio que pode ser entendido pelo posicionamento dos apartamentos no conjunto, ficando parte mais expostos a insolação no verão e partes mais protegidos. Oito usuários $(21,1 \%$ dos entrevistados) relataram sobre a elevação excessiva de temperatura nas vedações verticais no período de verão, afirmando que as paredes ficam muito quentes, aumentando a temperatura no interior da unidade;

- No que diz respeito à acústica, os ruídos oriundos do interior das unidades levou a maioria a classificar o conforto acústico no interior das unidades como "bom”, já quanto aos ruídos oriundos de fora do apartamento, o conforto acústico obteve classificação "regular". Fato que pode indicar um desempenho acústico diferenciado entre as vedações internas e externas do apartamento.

\subsubsection{Satisfação com a vedação vertical em parede de concreto}

Ao serem questionados à respeito da resistência das paredes, $58 \%$ dos respondentes avaliaram como "muito resistentes" e 37\% como "resistentes". Em relação à segurança de uso quanto à estrutura do edifício, $89 \%$ se sentem seguros; porém, $11 \%$ sentem alguma insegurança, principalmente, pela edificação estar situada em uma área de manguezal.

A fixação de objetos em paredes é ponto bastante crítico entre os usuários, conforme ilustra a Figura 3. Apesar da entrega por parte da construtora do manual de uso e operação da edificação, no qual consta a limitação da execução de furos nas paredes, diversos respondentes relataram sobre dificuldades de furar as paredes. 


\section{Fixação de objetos grande peso}

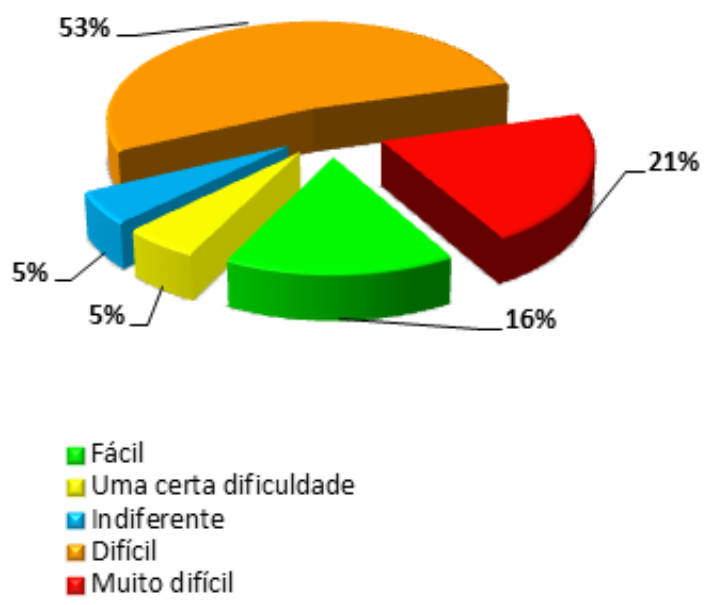

Fixação de objetos pequeno peso

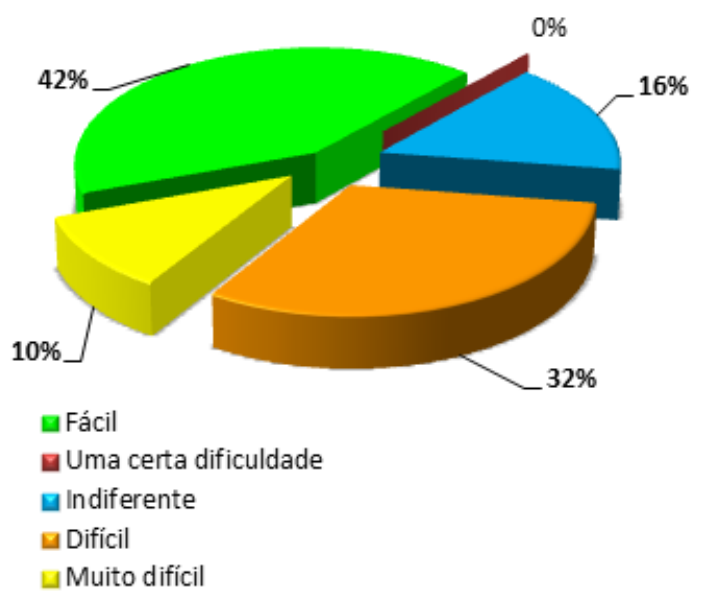

Figura 3. Dificuldade de fixação de objetos nas paredes.

Fonte: Os autores (2019)

A fixação de objetos de grande peso, como armários, nas paredes dos apartamentos apresentou-se difícil para a 53\% dos entrevistados. Já na fixação de objetos leves, 58\% dos usuários consideraram como fácil ou indiferente, não apresentando assim sinais de dificuldade. Entretanto, diversas adaptações foram relatadas para a fixação de objetos, como a utilização de fitas adesivas em quadros e decorações.

\subsubsection{Manifestações patológicas}

As manifestações patológicas mais comuns foram: $53 \%$ de umidade nas paredes, $37 \%$ de vazamento nas lajes e $16 \%$ de fissuras nas paredes.

Os principais casos de umidade em paredes concentram-se nos cômodos de sala e quarto, na área imediatamente inferior das janelas (Figura 4). As fissuras com queixas mais recorrentes estão situadas nos shafts de tubulações com fechamentos em placas de gesso acartonado no encontro com as paredes de concreto. Pôde-se ainda identificar fissuras na ligação entre as escadas e as paredes (Figura 5), causando mal estar e certa insegurança entre os moradores do condomínio.

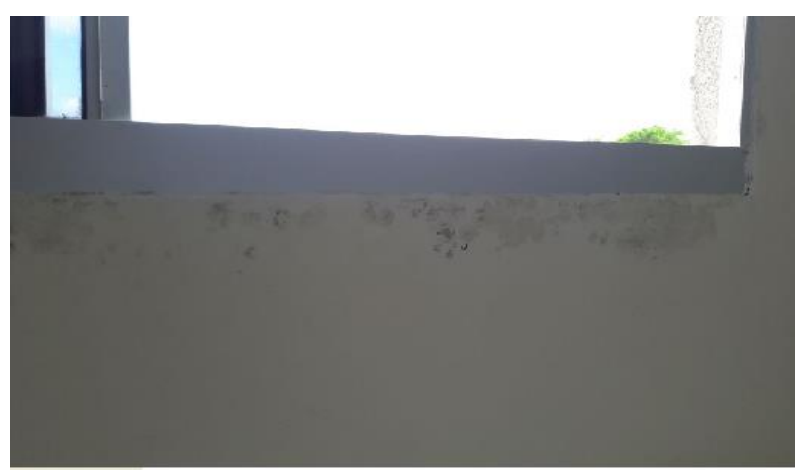

Figura 4. Presença de machas de umidade. Fonte: Os autores (2019)

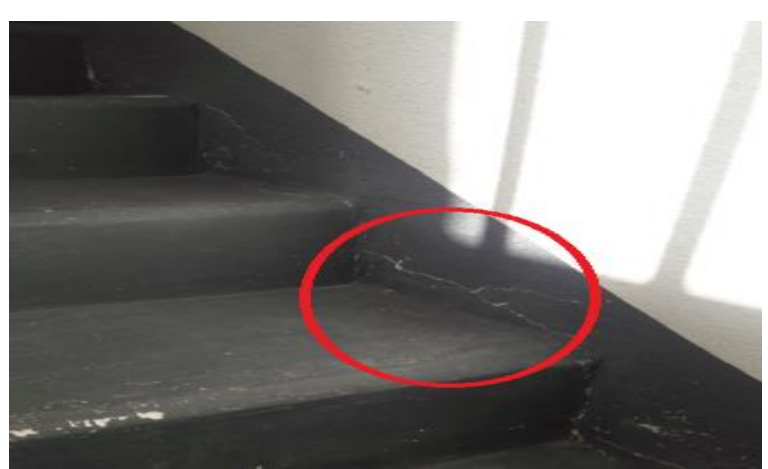

Figura 5. Fissura na interface parede/escada. Fonte: Os autores (2019)

\subsubsection{Desempenho da unidade habitacional}

A Figura 6 ilustra o nível de satisfação com a unidade habitacional, tendo sido considerada média pela maioria dos respondentes da pesquisa. 


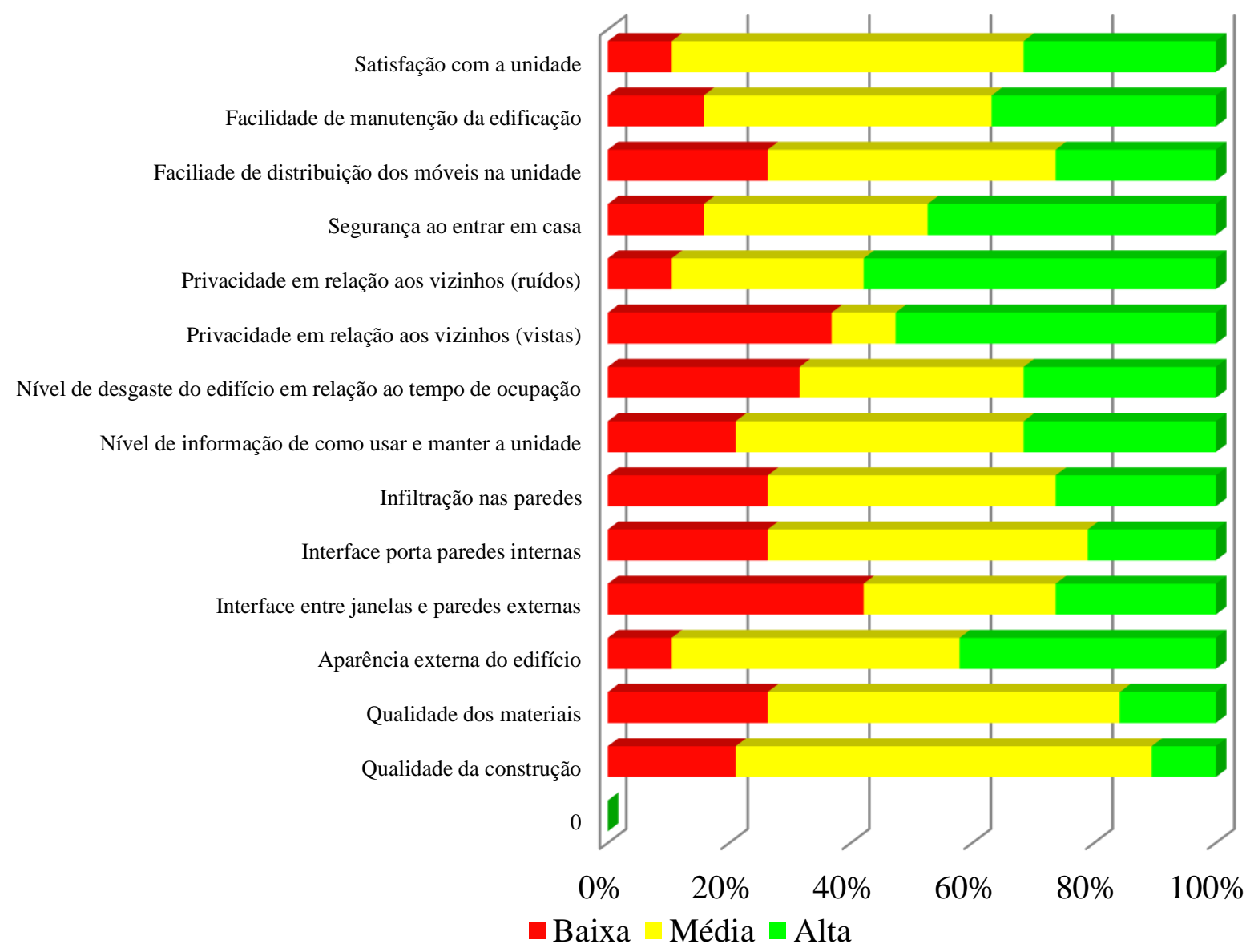

Figura 6. Satisfação com a unidade habitacional.

Fonte: Os autores (2019).

Dentre os itens de insatisfação, destacam-se os problemas de infiltração e as deficiências na interface entre as paredes internas/portas. A insatisfação relativa aos problemas de infiltração na interface paredes externas/janelas ocorre em ocasiões de chuvas intensas e, também pelo não respeito ao manual de uso e manutenção da edificação, existem diversos casos de perfuração de paredes para passagem de instalações, como por exemplo de ar-condicionado (Figura 7).

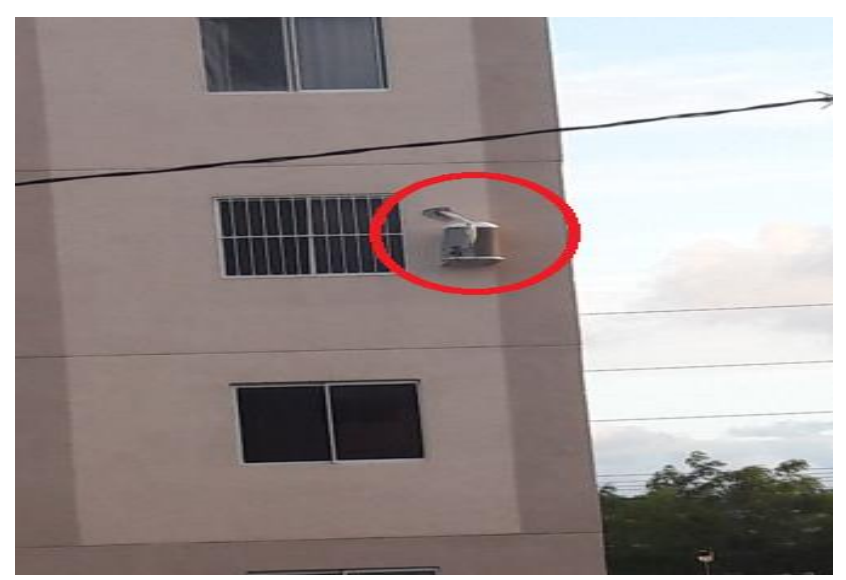

Figura 7. Perfuração irregular de paredes.

Fonte: Os autores (2019) 
Quanto à insatisfação relativa à interface entre as paredes internas/portas, 53\% dos entrevistados indicam satisfação "média", devido aos problemas na utilização da porta, com deficiência no fechamento.

\subsection{Estudo de caso 2}

\subsubsection{Caracterização do edifício com paredes de drywall}

O condomínio localiza-se na cidade de Recife, no Estado de Pernambuco, no nordeste do Brasil. A área total do empreendimento é de $11.794 \mathrm{~m}^{2}$, sendo composto por 02 edifícios, possuindo cada um dezessete pavimentos, sendo um pavimento térreo, um pavimento vazado, treze pavimentos tipo, um pavimento de cobertura e um pavimento de cobertura. Cada um dos treze pavimentos tipo possui quatro apartamentos (Figura 8), totalizando 104 unidades. No momento da realização da pesquisa haviam 74 unidades ocupadas.

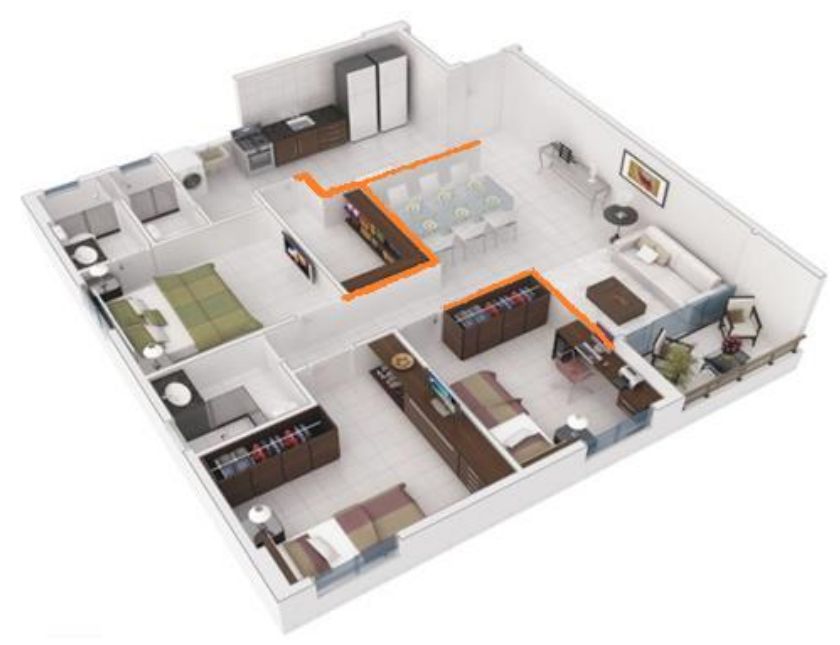

Figura 8. Planta baixa do apartamento com paredes de drywall ressaltadas em vermelho. Fonte: Construtora do estudo de caso 2 (2019).

\subsubsection{Motivo de escolha da unidade}

Os principais motivos de escolha da unidade habitacional elencados pelos respondentes foram em ordem decrescente: a localização do edifício, o tamanho do apartamento e o custo do mesmo. A localização privilegiada da edificação, situada em bairro nobre da cidade do Recife, foi citada por 30,16 $\%$ dos respondentes como fator primordial para escolha do apartamento, devido às comodidades ofertadas pelo entorno da região. Em seguida destaca-se o tamanho da unidade, citada por $23,81 \%$ dos entrevistados, com 3 quartos e $79 \mathrm{~m}^{2}$ de área privativa. Para 20,63\% dos usuários, o custo de aquisição do imóvel foi fator principal de decisão de compra.

\subsubsection{Conhecimento da tecnologia construtiva}

Dentre os 21 entrevistados, $43 \%$ (09 respondentes) revelaram já conhecer a referida tecnologia por meio de prévios convívios em edificações residenciais e empresariais; enquanto, 57\% (12 respondentes) responderam nunca ter tido contato ou conhecer o sistema em questão antes da compra de seus atuais imóveis. Dentre os usuários que responderam já ter tido contato com paredes em drywall, cinco afirmaram ter trabalhado em edificações empresariais que possuíam tais paredes, dois relataram terem o primeiro contato através de hospedagem em hotéis e outros dois indicaram ter conhecido o sistema em residências de amigos e familiares, evidenciando a pouca presença de tal tecnologia no âmbito residencial, ocasionando o pouco conhecimento e desconfiança por parte dos consumidores. 


\title{
3.2.4 Conforto ambiental
}

A Figura 9 ilustra o grau de satisfação dos usuários.

\author{
Divisões dos cômodos \\ Tamanho dos cômodos \\ Ventilação da edificação \\ Iluminação natural \\ Conforto térmico
}

Acústica em relação ao interior

Acústica em relação ao exterior

$\mathrm{O}$ que acha de morar aqui?

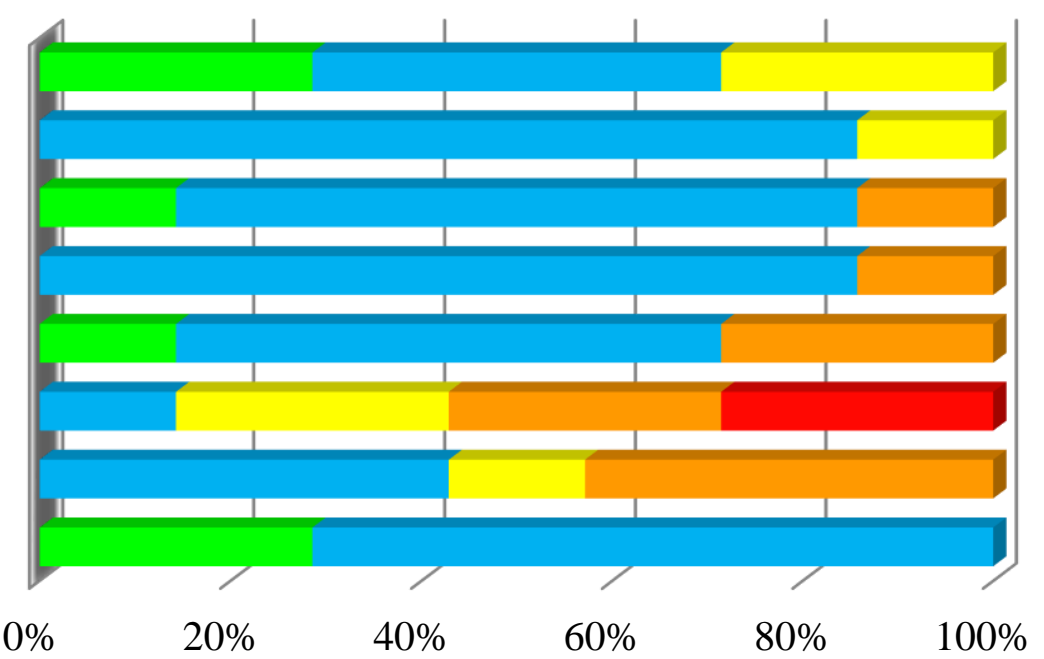

\section{- Muito bom $\square$ Bom $\square$ Regular $\square$ Ruim $\square$ Muito ruim}

Figura 9. Grau de satisfação dos usuários.

Fonte: Os autores (2019).

Destacam-se nas respostas da Figura 9:

- de modo geral os entrevistados demonstraram satisfação em residir em seus apartamentos, pois $29 \%$ responderam que consideram "muito bom" e $71 \%$ "bom" a experiência de morar em unidades com paredes em drywall;

- quanto à divisão dos cômodos, $29 \%$ consideraram "bom", $42 \%$ consideraram "muito bom" e $29 \%$ consideraram "regular". Foi citado como ponto positivo da disposição dos cômodos a presença de um quarto no centro do apartamento com possibilidade de ser revertido como closet para o quarto principal (suíte), o que de fato segundo os respondentes foi realizado;

- o tamanho dos cômodos foi um dos pontos positivos citados, sendo avaliado como "bom" por $86 \%$ dos respondentes; enquanto, $14 \%$ avaliaram apenas como "regular". Os usuários relataram que apesar de satisfeitos, o tamanho dos cômodos poderia ser acrescido se não houvesse o quarto central (reversível como closet) e o banheiro de serviço, justificando assim sua avaliação "regular";

- o empreendimento situa-se próximo a uma grande área verde, favorecendo a ventilação, a qual foi considerada muito boa por $14 \%$ dos entrevistados, boa por $71 \%$ e ruim por $14 \%$ dos respondentes;

- a iluminação foi considerada "boa" por $86 \%$ dos entrevistados e "ruins" por $14 \%$ deles. Já o conforto térmico foi considerado "muito bom" por $14 \%$, "bom" por $57 \%$ e "ruim" por $29 \%$. O grande número de usuários insatisfeitos com as temperaturas em seus lares indica que o posicionamento dos cômodos ou da própria edificação poderiam ter sido mais bem adaptado às condições naturais;

- de modo geral, a avaliação da acústica proveniente de sons oriundos do interior do apartamento gerou insatisfação dos usuários, onde muitos relataram que os sons gerados em qualquer cômodo da unidade podem ser ouvidos nos demais. Quando questionados se a referida situação ocorria nos cômodos com paredes em drywall, o descontentamento foi o mesmo. 


\subsubsection{Satisfação com a vedação vertical em drywall}

A maioria dos respondentes (57\%) desconhece as características e aspectos positivos do drywall, gerando desconfiança por nunca ter tido contato prévio ou informações sobre esta tipologia de vedação. A parede é vista, conforme figura 10, principalmente como frágil e oca, não passando a sensação de confiança a seus usuários, muitos destes inclusive relataram que a adoção de tal tecnologia se tratava de uma opção da construtora para reduzir custos. Tais fatos indicam a necessidade de disseminação do conhecimento, características e possibilidades que uma vedação em drywall pode trazer aos usuários, de modo que esta tipologia de parede seja vista como uma opção tecnológica benéfica ao usuário.

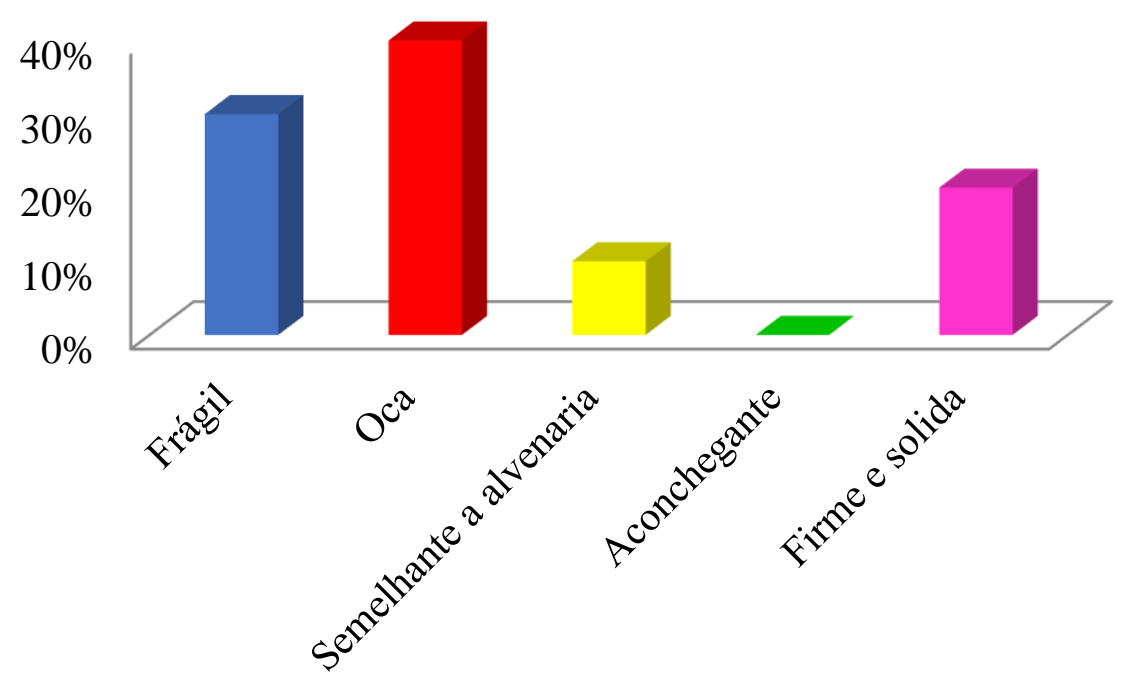

Figura 10. Percepção do usuário quanto ao drywall. Fonte: Os autores (2019).

A percepção da resistência pelos respondentes também foi alvo de investigação, e resultou na avaliação de $29 \%$ dos usuários como "resistente", $57 \%$ como "regular" e $14 \%$ como uma vedação "pouco resistente".

Objetos de grande peso foram considerados de fácil fixação por $71 \%$ dos entrevistados; enquanto, $29 \%$ avaliaram como indiferente a dificuldade de fixação (Figura 11). Tal fato se justifica pelo receio de realizar furações nas paredes em locais não apropriados e também pela ausência de segurança na capacidade de resistência da parede com relação a sustentar objetos pesados. A fixação de objetos de pequeno peso teve exatamente mesma avaliação da fixação de objetos de grande peso. Cabe ressaltar que moradores utilizaram diversos recursos para fixação de objetos, desde a utilização de fitas adesivas para fixação de quadros decorativos, como a contratação de empresas especializadas em drywall para correta colocação de acessórios de suporte para objetos mais pesados.

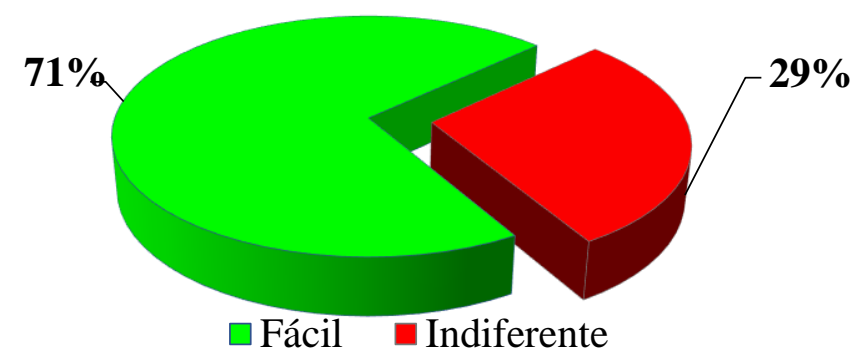

Figura 11. Dificuldade de fixação de objetos nas paredes. Fonte: Os autores (2019). 


\subsubsection{Manifestações patológicas}

Durante a realização das entrevistas nenhum usuário relatou qualquer tipo de problemas ou inconvenientes relacionados com a presença de fissuras nas vedações em drywall, descolamento de revestimento ou presença de manchas de umidade.

\subsubsection{Desempenho da unidade habitacional}

De modo geral, a satisfação com a unidade habitacional foi considerada "alta", como se pode observar através da Figura 12. Destacam-se positivamente os aspectos relacionados ao desgaste do edifício com relação ao tempo de uso, ausência de infiltração nas paredes e aparência externa do edifício.

Entretanto, destacam-se negativamente a privacidade com relação aos ruídos provenientes de unidades vizinhas; a privacidade com relação aos vizinhos e o nível de informação à respeito do uso e manutenção, especialmente das paredes em drywall.

Satisfação com a unidade

Facilidade de manutenção da edificação

Faciliade de distribuição dos móveis na unidade

Segurança ao entrar em casa

Privacidade em relação aos vizinhos (ruídos)

Privacidade em relação aos vizinhos (vistas)

Desgaste do edifício em relação ao tempo

Nível de informação uso e mantenção

Infiltração nas paredes

Interface porta paredes internas

Interface entre janelas e paredes externas

Aparência externa do edifício

Qualidade dos materiais

Qualidade da construção

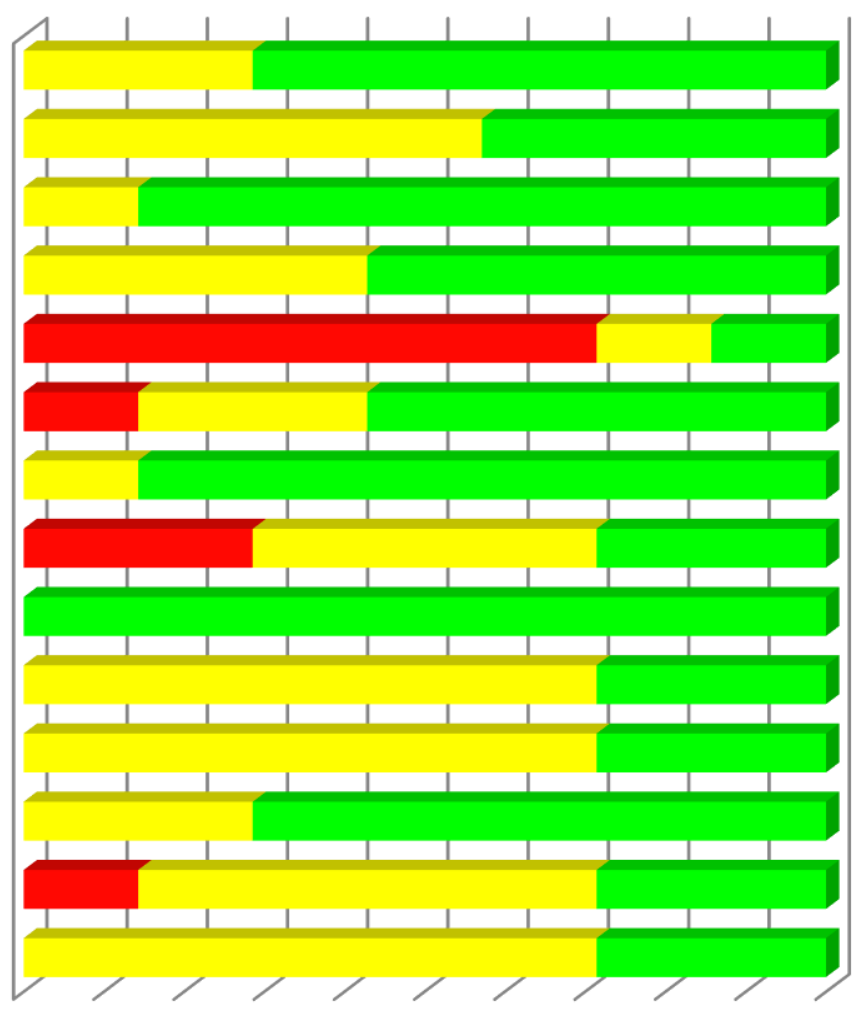

0\% 10\% 20\% 30\% 40\% 50\% 60\% 70\% 80\% 90\%100\%

- Baixa Média Alta

Figura 12. Satisfação com a unidade habitacional.

Fonte: Os autores (2019).

\section{CONCLUSÕES}

O curto prazo de execução da obra e a alta produtividade característica da tipologia de vedação vertical em paredes monolíticas de concreto não comprometem a qualidade geral da obra, mas geram problemas pontuais, principalmente, em regiões de abertura nas paredes, podendo desencadear uma série de manifestações patológicas.

Apesar do alto índice de informação sobre o correto uso e manutenção de suas paredes, diversos respondentes realizaram intervenções danosas às vedações, podendo por vezes propiciar o surgimento 
de manifestações patológicas, comprometer a estrutura da edificação, sendo necessário maior rigor da administração do condomínio quanto à fiscalização desta situação.

A avaliação pós-ocupação realizada é referência importante para a revisão e a atualização dos projetos e especificações da construtora, podendo em obras futuras definir soluções que evitem as intervenções observadas nas vedações dos estudos de caso, as quais além de comprometer o bem estar do usuário, podem trazer prejuízos à construtora, em especial ao setor de manutenção.

Quanto às vedações verticais em paredes de concreto moldadas no local, percebeu-se pelos resultados da pesquisa que a redução de custos e prazos compensam possíveis limitações arquitetônica,s como a redução de área da unidade, divisão e tamanho dos cômodos. De modo geral, os usuários encontram-se satisfeitos com as vedações de suas unidades, demonstrando a boa aceitação durante a fase de uso da edificação.

Quanto às vedações verticais em drywall, percebeu-se pelos resultados da pesquisa que ainda há muito desconhecimento relativo à tecnologia, sendo pouco divulgado os benefícios potenciais aos usuários. A divulgação de informações referentes ao uso e manutenção das vedações em drywall é outro elemento essencial para a correta utilização destas vedações pelos usuários, sendo necessário extrapolar a entrega de manual de uso e manutenção, através de ações que promovam a disseminação do conhecimento. Percebeu-se ainda que os usuários com conhecimento ou convívio prévio com drywall identificam os aspectos positivos e vantagens desta tecnologia mais facilmente, e fazem uso das potencialidades aproveitando a vedação de forma mais espontânea. De modo geral, apesar das dificuldades quanto à fixação de objetos e problemas relacionados a acústica, os usuários encontram-se satisfeitos com as vedações em drywall, principalmente devido à ausência de manifestações patológicas e flexibilidade de opções de layout.

\section{REFERÊNCIAS}

Almeida, H. R. (2018), “Inovações tecnológicas em edificações habitacionais: avaliação pós-ocupação das vedações verticais", Dissertação (Mestrado) - Escola Politécnica, Universidade de Pernambuco. Recife, p. 96.

Almeida, M. O., Sousa, J. G., Ceotto, B. S., Luz, P. (2014), “Utilização da NBR 9452 em inspeção predial de patologías" in: Encontro luso-brasileiro de degradação em estruturas de concreto armado, Salvador: BA (BRASIL).

Associação Brasileira de Normas Técnicas (2013). NBR 15575: Edificações habitacionais Desempenho. Rio de Janeiro.

Bonin, L. C., Amorim, S. R. L. (2006), “Inovação tecnológica na construção habitacional”. Porto Alegre: ANTAC, 2006.

Brasil (2017), "Relatório de avaliação da execução de programa de governo $n^{\circ}$ 66. Programa Minha Casa Minha Vida - FGTS”. Disponível em: < https://auditoria.cgu.gov.br/download/9775.pdf>. Acesso em 10 de dezembro de 2017.

Campos, H. C., Souza, H. A. (2011), “Avaliação Pós-Ocupação de Edificações estruturadas em aço, com foco em edificações em Light Steel Framing", in: Congresso Latino-Americano da Construção Metálica, São Paulo: SP (BRASIL).

Ecker, T. W.P., Martins, V. (2014), "Comparativo dos sistemas construtivos steel frame e wood frame para habitações de interesse social”, Pato Branco, 2014. Trabalho de conclusão de curso (Graduação) - Universidade Tecnológica Federal do Paraná.

Federação das Indústrias do Estado de São Paulo - FIESP (2019), "Construbusiness 2018. Evolução dos investimentos em obras e do PIB da cadeia produtiva da construção", Disponível em: $<$ http://az545403.vo.msecnd.net/observatóriodaconstrucao/2018/09/PIB-da-construcao2007_2018.pdf>. Acesso em: 10 mar. 2019.

Lakatos, E. M., Marconi, M. A. (2007), “Metodologia científica”. São Paulo: Atlas, 2007. 
Mello, C. W. (2004), “Avaliação de sistemas construtivos para habitações de interesse social”, Porto Alegre, 2004. Dissertação (Mestrado) - Universidade Federal do Rio Grande do Sul.

Mello, L.C. B. B., Amorim, S. R. L. (2009), O subsetor de edificações da construção civil no Brasil: uma análise comparativa em relação à União Europeia e aos Estados Unidos. Produção. 9(2):388-399. Ministério das Cidades (2019), "Desempenho técnico para HIS - SINAT Sistemas convencionais e innovadores", Disponível em: <http://app.cidades.gov.br/catalogo/>. Acesso em 28 de abril de 2019.

Morais, G. A. T. (2019), "Desempenho das edificações habitacionais: implementação e diretrizes", Recife, 2019. Dissertação (Mestrado) - Escola Politécnica, Universidade de Pernambuco.

Ochoa, C. (2015), "Amostragem: o que é $e$ por quê funciona”. Disponível em: $<$ https://www.netquest.com/blog/br/blog/br/amostragem-porque-funciona>. Acesso em 8 de julho de 2015.

Ornstein, S. W. (2017), Avaliação pós-ocupação no Brasil, 30 anos: O que há de novo? Revista Projetar, 2(2).

Pinho, S.A.C. (2013), "Desenvolvimento de programa de indicadores de desempenho para tecnologias construtivas à base de cimento: perdas, consumo e produtividade", Recife, 2013. Dissertação (Mestrado) - Escola Politécnica, Universidade de Pernambuco.

PROCON (2015), "Cadastro de reclamações fundamentadas". Disponível em: <http://www.procon.sp.gov.br/reclamacoes.asp.>. Acesso em 10 de junho de 2015.

Rheingantz, P. A. et al. (2009), “Observando a Qualidade do Lugar: Procedimentos para a avaliação pós-ocupação", Universidade Federal do Rio de Janeiro - Faculdade de Arquitetura e Urbanismo. Rio de Janeiro, 2009. 